\title{
A Facile Thermolysis Route to Monodisperse Ferrite Nanocrystals
}

Ningzhong Bao,* Liming Shen, Yuhsiang Wang, Prahallad Padhan, Arunava Gupta*

Center for Materials for Information Technology, University of Alabama, Tuscaloosa, AL 35487

\section{Experimental details:}

Materials: The synthesis of the ferrite nanocrystals was carried out using commercially available reagents. All the chemicals, including absolute ethanol, hexane, oleic acid, 1octadecene(90\%), sodium oleate $(95+\%), \mathrm{NiCl}_{2} \cdot 6 \mathrm{H}_{2} \mathrm{O}(99+\%), \mathrm{MnCl}_{2}(99+\%), \mathrm{FeCl}_{3}(99+\%)$, $\mathrm{CoCl}_{2}(97+\%)$, and $\mathrm{CuCl}_{2}(99+\%)$ were purchased from Fisher Scientific. They were used asreceived without any further purification.

Chemical safety and hazards: As per the information from the Material Safety Data Sheets (MSDS): 1-octadecene may cause eye and skin irritation and cause respiratory and digestive tract irritation. The toxicological properties of this material have not been fully investigated. Oleic acid causes eye, skin, and respiratory tract irritation. Sodium oleate has little or no health hazards. All the reported experimental procedures were carried out in a fume hood with appropriate handling of the chemicals.

Synthesis of metal oleate complexes: The mixed metal $\left(\mathrm{M}^{2+} \mathrm{Fe}_{2}{ }^{3+}\right)$-oleate complexes (expressed as $\mathrm{M}^{2+} \mathrm{Fe}_{2}{ }^{3+}\left(\mathrm{C}_{18} \mathrm{H}_{33} \mathrm{O}_{2}\right)_{8}{ }^{-}$, where $\mathrm{M}^{2+}$ are $\mathrm{Co}^{2+}, \mathrm{Ni}^{2+}, \mathrm{Mn}^{2+}, \mathrm{Fe}^{2+}$, and $\left.\mathrm{Cu}^{2+}\right)$ were prepared by reaction of sodium oleate and the respective metal chlorides (the mixture of $\mathrm{Fe}^{3+}$ and $\mathrm{M}^{2+}=\mathrm{Co}^{2+}$, $\mathrm{Ni}^{2+}, \mathrm{Mn}^{2+}, \mathrm{Fe}^{2+}$ and $\left.\mathrm{Cu}^{2+}\right)$. For example, in the synthesis of $\mathrm{Co}^{2+} \mathrm{Fe}_{2}{ }^{3+}\left(\mathrm{C}_{18} \mathrm{H}_{33} \mathrm{O}_{2}\right)_{8}{ }^{-}, 4 \mathrm{mmol}$ $\mathrm{FeCl}_{3}, 2 \mathrm{mmol} \mathrm{CoCl}_{2}, 16 \mathrm{mmol}$ sodium oleate $\left(\mathrm{C}_{18} \mathrm{H}_{33} \mathrm{NaO}_{2}\right), 10 \mathrm{ml} \mathrm{H} \mathrm{H}_{2} \mathrm{O}, 10 \mathrm{ml}$ ethanol and 20 
$\mathrm{ml}$ hexane were mixed and refluxed at $60^{\circ} \mathrm{C}$ for $4 \mathrm{~h}$. The mixed $\mathrm{Co}^{2+} \mathrm{Fe}_{2}{ }^{3+}$-oleate complex $\left(\mathrm{CoFe}_{2}\left(\mathrm{C}_{18} \mathrm{H}_{33} \mathrm{O}_{2}\right)_{8}\right)$ was obtained by the separation of the water phase and subsequent evaporation of the residual ethanol and hexane at $70^{\circ} \mathrm{C}$, and water at $110^{\circ} \mathrm{C}$.

Synthesis of monodisperse ferrite nanocrystals: In a $125 \mathrm{ml}$ three-neck spherical-bottom flask, $5 \mathrm{~g}$ of the mixed metal $\left(\mathrm{M}^{2+} \mathrm{Fe}_{2}{ }^{3+}\right)$-oleate complex was dissolved in $20 \mathrm{ml}$ 1-octadecene containing $0.4 \mathrm{~g}$ oleic acid by stirring for 1 hour under flowing $\mathrm{N}_{2}$. The mixture was then heated to $300^{\circ} \mathrm{C}$ at a heating rate of $3^{\circ} \mathrm{C} / \mathrm{min}$, and maintained at this temperature for 30 minutes, under $\mathrm{N}_{2}$ flow with continuous stirring. The reaction mixture was subsequently cooled to room temperature and transferred to a $50 \mathrm{ml}$ centrifuge tube, together with $20 \mathrm{ml}$ mixture of ethonal and hexane with a volume ratio of 1:3. A black precipitate was obtained by centrifugation at $8000 \mathrm{rpm}$ for 15 minutes. Thermolysis of a $5 \mathrm{~g}$ mixed $\mathrm{M}^{2+} \mathrm{Fe}_{2}{ }^{3+}\left(\mathrm{C}_{18} \mathrm{H}_{33} \mathrm{O}_{2}\right)_{8}{ }^{-}$metal oleate complex resulted in the formation of about $0.5 \mathrm{~g} \mathrm{MFe}_{2} \mathrm{O}_{4}$ nanoparticles. After several washings with $30 \mathrm{ml}$ hexane, the concentration of organic residue was determined to be less than $5 \%$ organic by calcination of the products at $500{ }^{\circ} \mathrm{C}$ in air for 1 hour. Except for the formation of $\mathrm{Cu}$ nanoparticles from the thermolysis of $\mathrm{Cu}^{+} \mathrm{Fe}_{2}{ }^{3+}\left(\mathrm{C}_{18} \mathrm{H}_{33} \mathrm{O}_{2}\right)_{8}^{-}$complexes, monodisperse ferrrite $\left(\mathrm{MFe}_{2} \mathrm{O}_{4}, \mathrm{M}=\mathrm{Co}, \mathrm{Ni}, \mathrm{Mn}\right.$, and $\left.\mathrm{Fe}\right)$ nanocrystals were obtained for all the other mixed oleate systems.

\section{High resolution TEM analysis:}

The HRTEM image (Figure 1A2) of a single cubic $\mathrm{CoFe}_{2} \mathrm{O}_{4}$ nanocrystal shows lattice fringes with measured interlayer spacing of $0.297 \pm 0.003 \mathrm{~nm}$, which matches with the lattice spacing of the [220] planes. Similarly, from the HRTEM images of $\mathrm{NiFe}_{2} \mathrm{O}_{4}$ (Figure 1B2), $\mathrm{MnFe}_{2} \mathrm{O}_{4}$ (Figure 
1C2) and $\mathrm{FeFe}_{2} \mathrm{O}_{4}$ (Figure 1D2), the interlayer distance between adjacent lattice fringes are measured to be $0.207 \pm 0.003,0.217 \pm 0.002$, and $0.484 \pm 0.004 \mathrm{~nm}$, respectively. These are very close to the respective lattice spacing of the [400] planes at $0.209 \mathrm{~nm}$, the [400] planes at 0.214 $\mathrm{nm}$, and [111] planes at $0.485 \mathrm{~nm}$ for the three spinels.
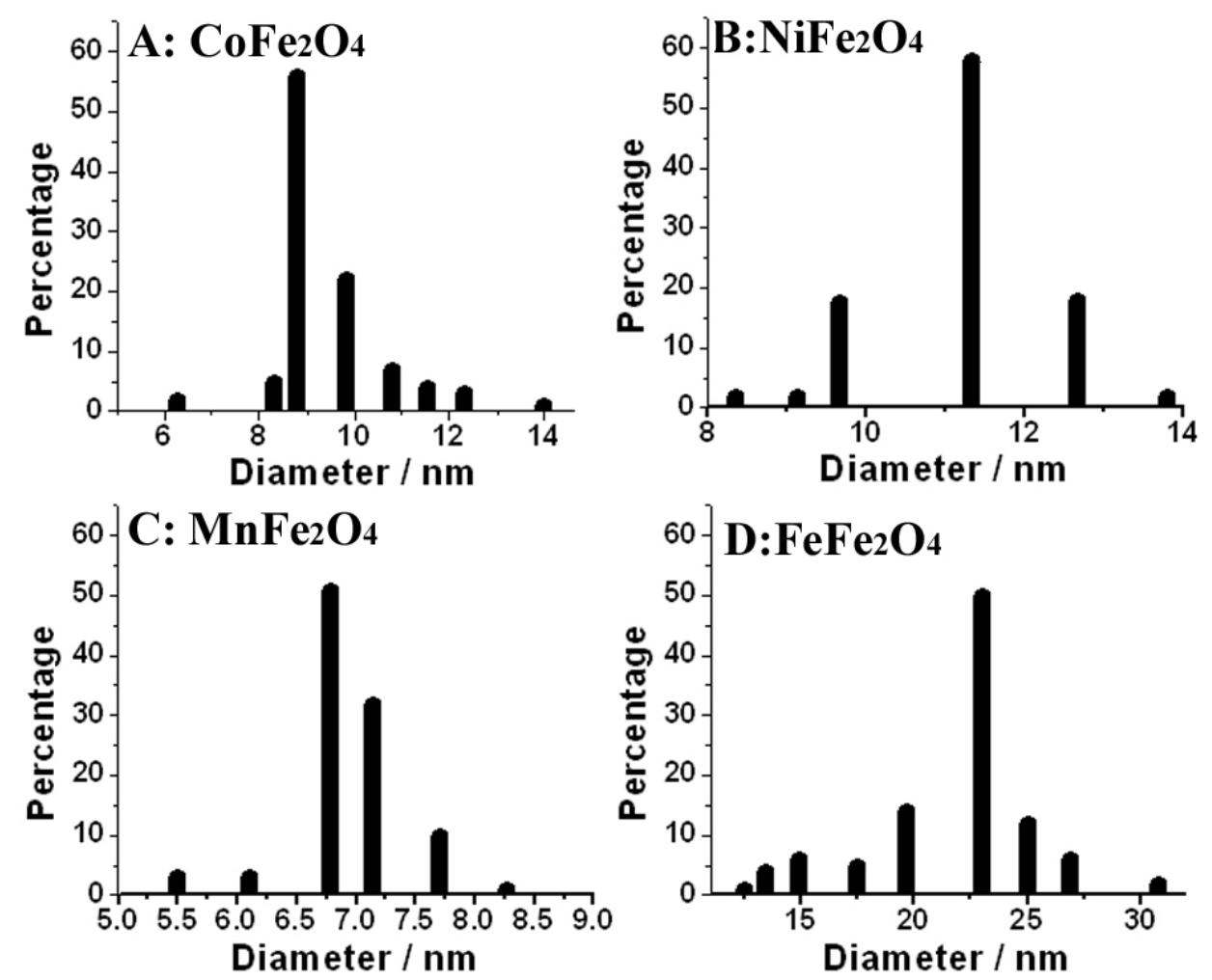

SI1: Size distribution of nanocrystals of: (A) $\mathrm{CoFe}_{2} \mathrm{O}_{4}$; (B) $\mathrm{NiFe}_{2} \mathrm{O}_{4}$; (C) $\mathrm{MnFe}_{2} \mathrm{O}_{4}$; and (D) $\mathrm{FeFe}_{2} \mathrm{O}_{4}\left(\mathrm{Fe}_{3} \mathrm{O}_{4}\right)$. 

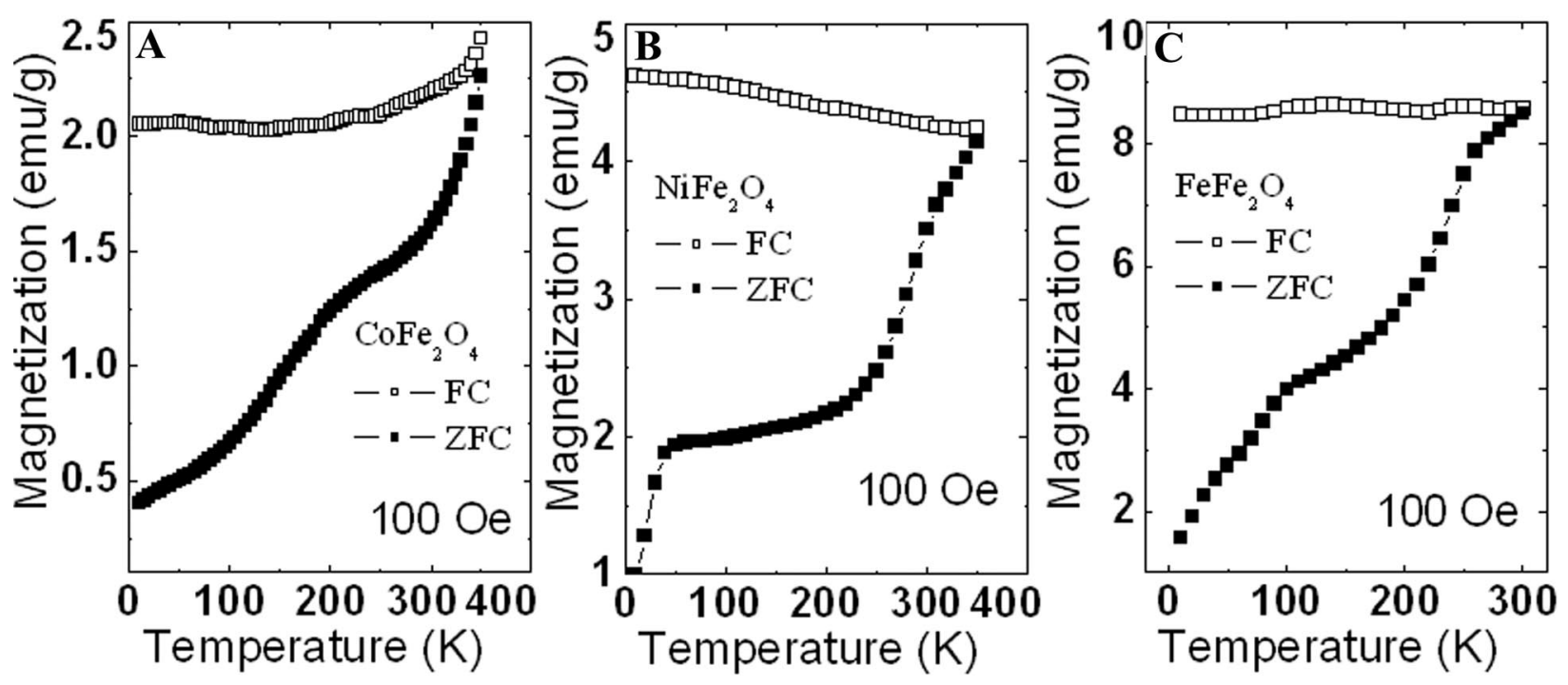

SI2: Field-cooled (FC) and zero-field cooled (ZFC) magnetization data as a function of temperature for (A) $\mathrm{CoFe}_{2} \mathrm{O}_{4},(\mathrm{~B}) \mathrm{NiFe}_{2} \mathrm{O}_{4}$, and (C) $\mathrm{Fe}_{3} \mathrm{O}_{4}$ nanocrystals measured in an applied field of 100 Oe.

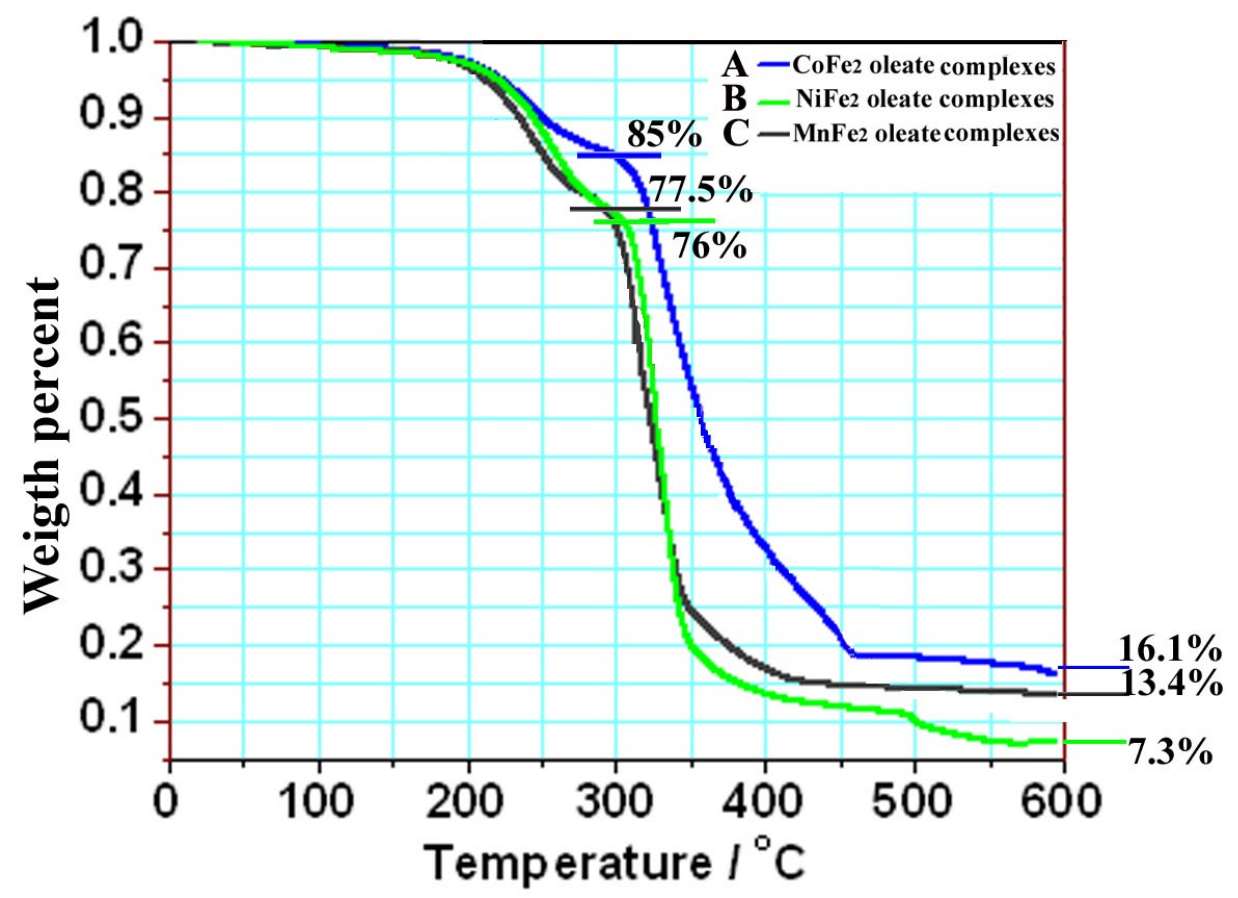

SI3: Thermogravimetric analysis (TGA) curves for $(\mathrm{A}) \mathrm{Co}^{2+} \mathrm{Fe}_{2}{ }^{3+}-,(\mathrm{B})(\mathrm{NiMn})^{2+} \mathrm{Fe}_{2}{ }^{3+}-$, and $(\mathrm{C})$ $(\mathrm{Mn})^{2+} \mathrm{Fe}_{2}{ }^{3+}$ - oleate complexes. 


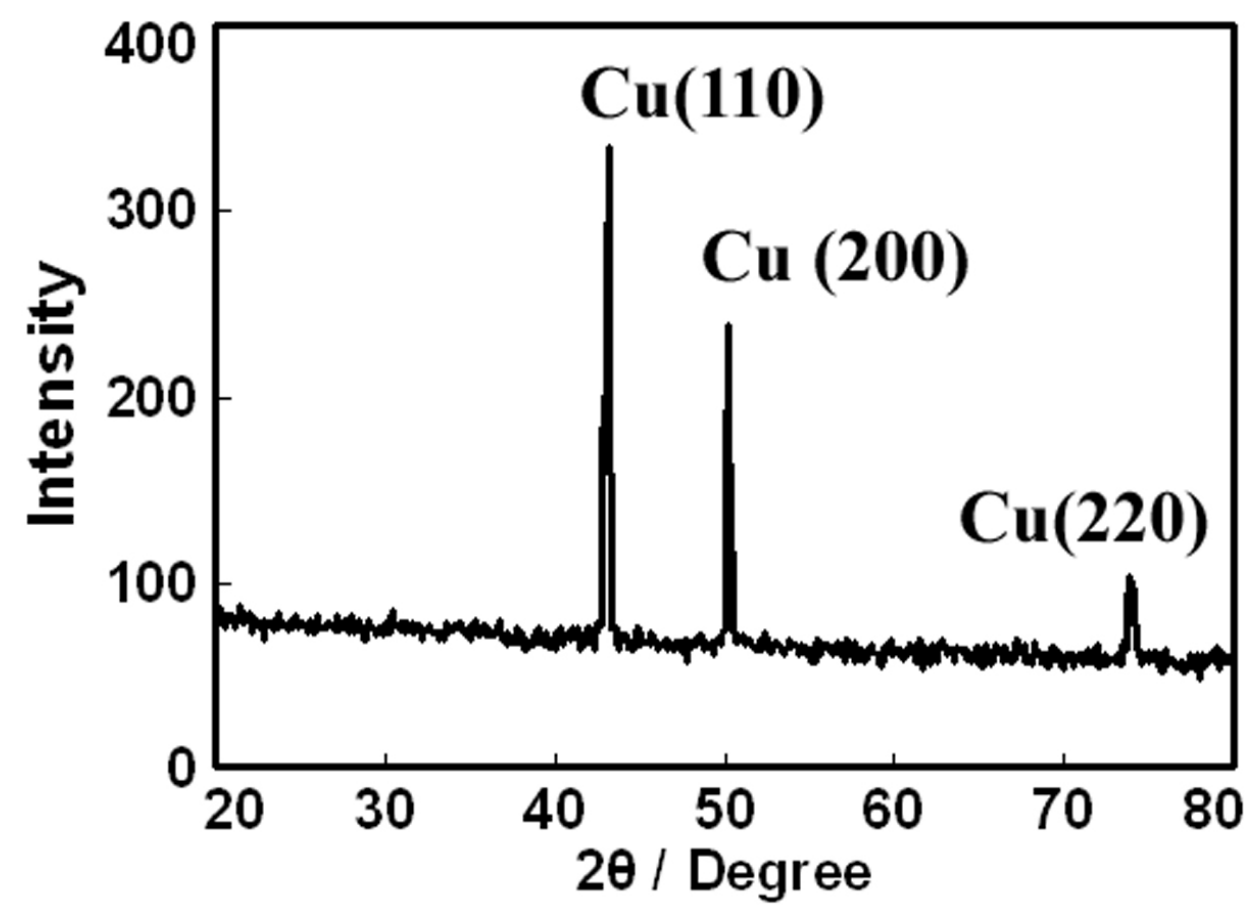

SI4: XRD patterns of $\mathrm{Cu}$ nanoparticles obtained by separation of the thermolysis product of $\mathrm{Cu}^{2+} \mathrm{Fe}_{2}{ }^{3+}$-oleate complex at $250{ }^{\circ} \mathrm{C}$.

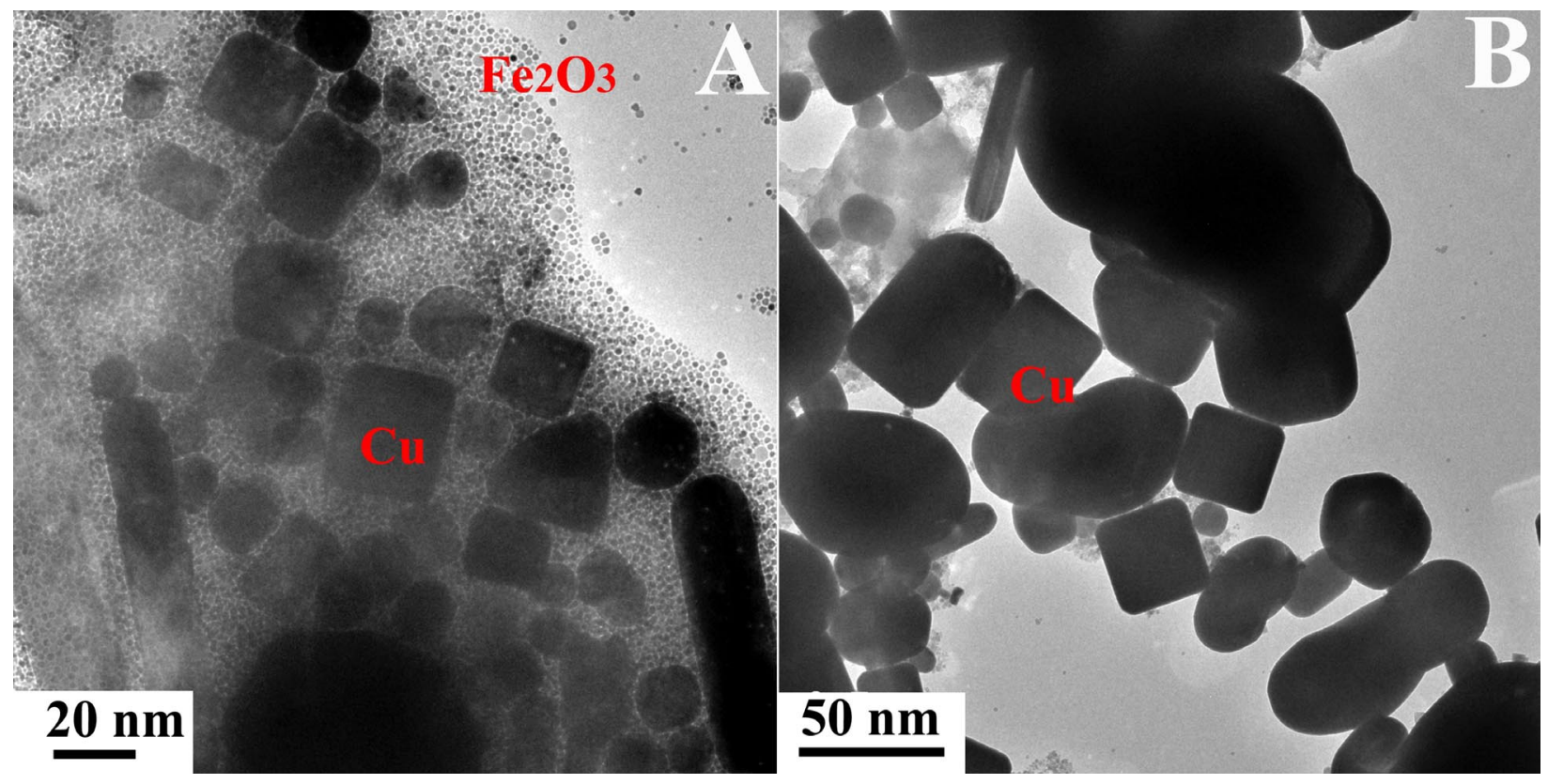

SI5: TEM image of: (A) the $\mathrm{Cu}$ and $\mathrm{Fe}_{2} \mathrm{O}_{3}$ nanoparticles synthesized by thermolysis of $\mathrm{Cu}^{2+} \mathrm{Fe}_{2}{ }^{3+}$-oleate complex at $300^{\circ} \mathrm{C}$, and (B) the $\mathrm{Cu}$ nanoparticles from the thermolysis products of $\mathrm{Cu}^{2+}$-oleate complexes at $250{ }^{\circ} \mathrm{C}$. 


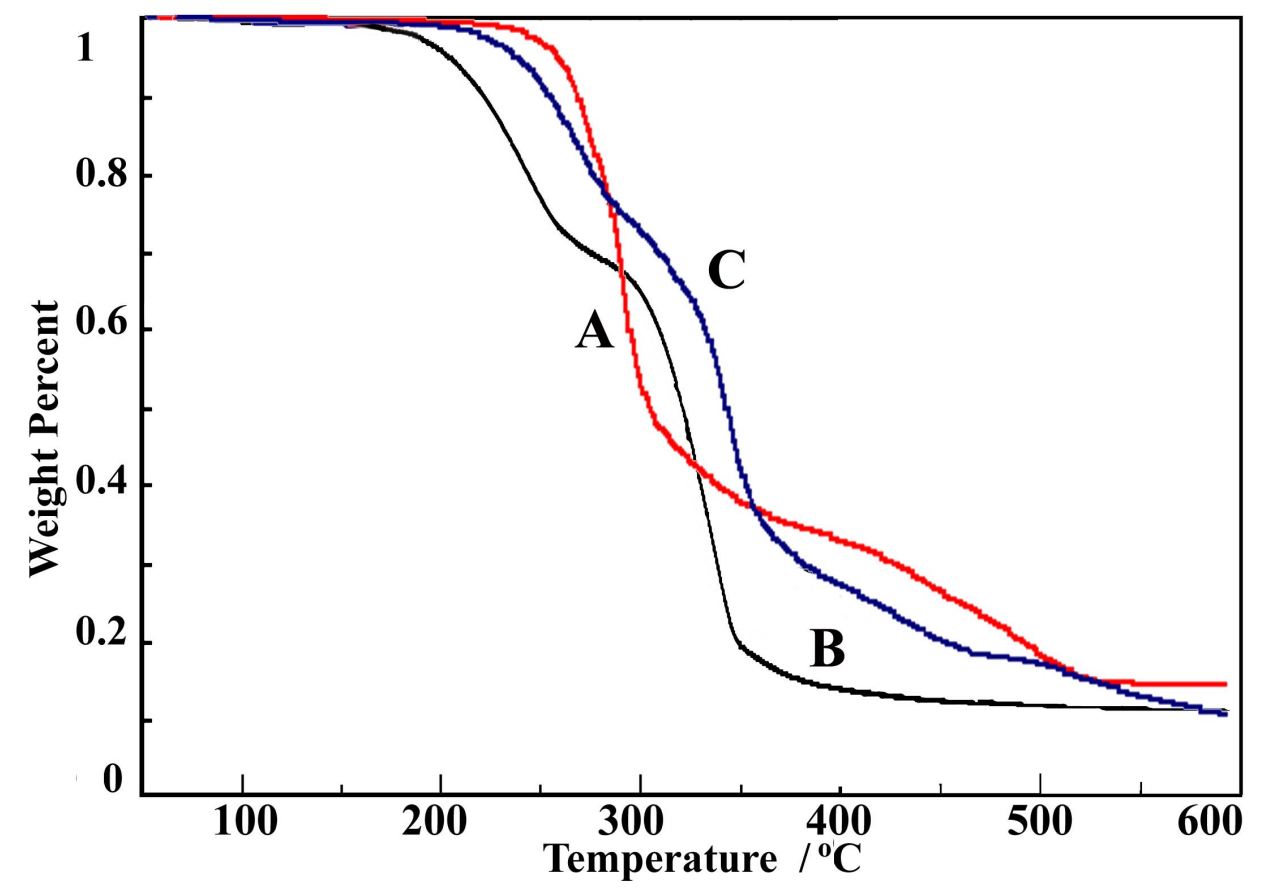

SI6: TGA curves of: (A) $\mathrm{Cu}^{2+}$-oleate, (B) $\mathrm{Fe}^{3+}$-oleate, and (C) mixed $\mathrm{Cu}^{2+} \mathrm{Fe}_{2}{ }^{3+}$-oleate complex.

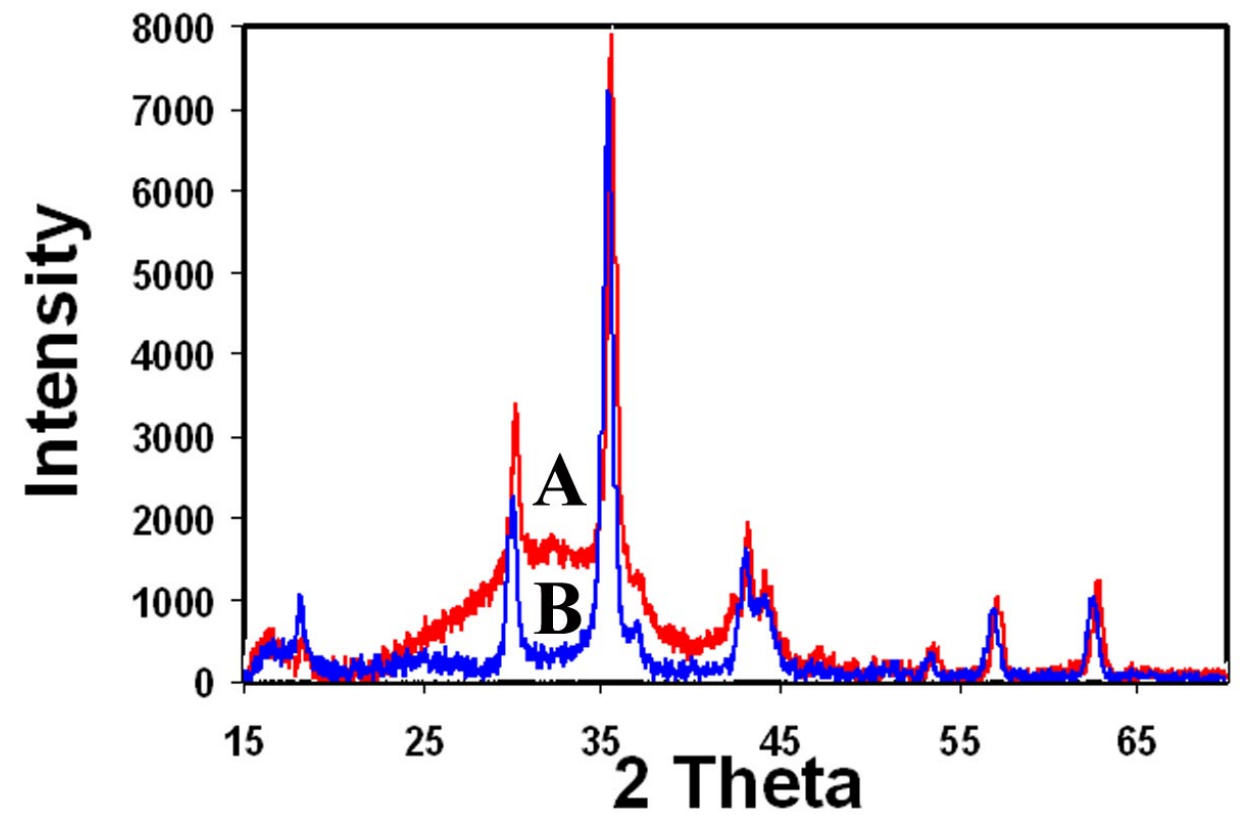

SI7: XRD patterns of $\mathrm{CoFe}_{2} \mathrm{O}_{4}$ synthesized by thermolysis of: (A) binary $\mathrm{Co}^{2+} \mathrm{Fe}_{2}{ }^{3+}$-oleate complex, and (B) the mixture of separately prepared $\mathrm{Co}^{2+}$-oleate and $2 \mathrm{Fe}^{3+}$-oleate complexes in 1 -octadecene at $300^{\circ} \mathrm{C}$. 


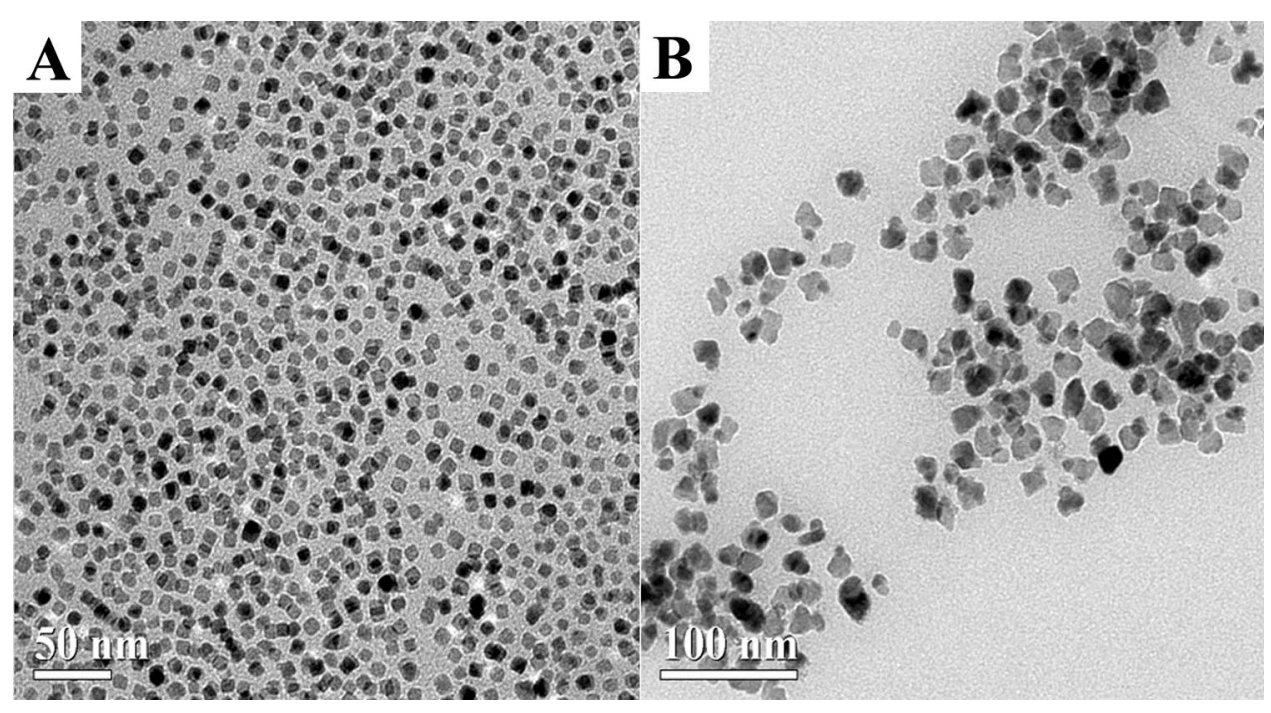

SI8: TEM images of $\mathrm{CoFe}_{2} \mathrm{O}_{4}$ synthesized by thermolysis of: (A) binary $\mathrm{Co}^{2+} \mathrm{Fe}_{2}{ }^{3+}$-oleate complex, and $(\mathrm{B})$ the mixture of separately prepared $\mathrm{Co}^{2+}$-oleate and $2 \mathrm{Fe}^{3+}$-oleate complexes in 1 -octadecene at $300^{\circ} \mathrm{C}$. 